\section{Dendritische Zelle}

H. Renz ${ }^{1}$ und B. Gierten ${ }^{2}$

${ }^{1}$ Institute of Laboratory Medicine and Pathobiochemistry,

Molecular Diagnostics, Philipps University Marburg,

University Hospital Gießen and Marburg GmbH, Marburg,

Deutschland

${ }^{2}$ Institut für Medizinische Diagnostik $\mathrm{GmbH}$, Immunologie,

Bioscientia, Ingelheim, Deutschland

Synonym(e) Langerhans-Zelle; plasmozytoide dendritische Zelle; DC; antigenpräsentierende Zelle
Englischer Begriff dendritic cell; antigen-presenting cell (APC)

Definition Subpopulation antigenpräsentierender Zellen.

Funktion - Pathophysiologie APC ( $\triangleright$ Antigenpräsentierende Zellen). Oberflächenmarker: CD1a, CD1b, CD1c.

Untersuchungsmaterial - Entnahmebedingungen Heparinblut.

Analytik Durchflusszytometrie.

Der Parameter wird derzeit ausschließlich im Rahmen von Forschungsanwendungen untersucht. 